\title{
NETWORK DESIGN AND CHANNEL STRATEGIES
}

\author{
GERARD DE VILLIERS \\ Arup (Pty) Ltd, Johannesburg, South Africa
}

\begin{abstract}
Supply chains compete and not products, commodities or companies. Transport is of particular importance in logistics and supply chain management as transport costs are the largest cost component and probably the most important logistics function in the supply chain. The design of logistics networks and the development of appropriate channel strategies should consequently be an integral part of transportation planning and modelling.

This chapter starts with an introduction that explains the importance of network design and channel strategies in transportation modelling. It continues with a description of logistics and supply chain management and follows with the importance of the planning hierarchy. The next part covers the distribution channel and the different alternative options with practical examples. It also includes the implication of using intermediaries in the distribution channel as well as the role of third-party and fourth-party logistics service providers.

Location analysis covers some of the relevant theories on macro level as well as specific questions to be addressed on micro level. Logistics network design explains the trade-offs in determining the number of facilities and it also suggests typical outbound distribution strategies that are used.

The next part covers centre-of-gravity analysis. This type of heuristic modelling is done with spreadsheets without dedicated optimisation software. Mathematical formulae for the optimisation of the locations are explained and a practical example was included showing the calculations in tabular and graphical format. This is followed with a discussion on total logistics costs.

This chapter ends with reference to different channel strategies once the location and total logistics costs have been determined.

Keywords: centre-of-gravity analysis, channel strategy, distribution channel, fourth-party logistics, location analysis, logistics, network design, planning hierarchy, supply chain management, third-party logistics, and total logistics costs.
\end{abstract}

\section{INTRODUCTION}

The design of a logistics network and the configuration of the appropriate supply chain strategy to serve the network, are important prerequisites for the successful development of efficient supply chains. Christopher [1] suggests that leading-edge companies realised that the real competition is not company against company but rather supply chain against supply chain. This implies that suitable network design and channel strategies should receive due attention in the transportation modelling stage of the development of master plans and other development frameworks.

Cost of logistics is another key performance indictor of the supply chain that has to be carefully monitored and managed to be able to allow the supply chains to compete effectively. The CSIR [2] found in their latest annual State of Logistics Survey for South Africa that total logistics costs as a percentage of GDP remained constant at $12.5 \%$ since 2011. However, due primarily to fuel inflation, they expect a small increase to $12.8 \%$ in 2014 . This remains considerably higher than the figure of $8.2 \%$ in 2013 for the USA [3]. A breakdown of the components of the latest logistics costs in South Africa is estimated for 2014:

- Transport:

- Inventory carrying costs: 
- Management and administration: $12.4 \%$

- Warehousing: $\quad 12.3 \%$

The transport costs of $58.8 \%$ are exceptionally higher that the global average of $39 \%$, but can partially be explained by the spatially challenged economy, largely driven by fuel and wages. The high transport cost confirms the need for careful planning for transportation and hence explains the importance of efficient network design and appropriate channel strategies.

\section{LOGISTICS AND SUPPLY CHAIN MANAGEMENT}

Various definitions of logistics and supply chain management are applied in practice and it might be useful to use a diagram to explain the concepts as used for purpose of this discussion. This is presented in Fig. 1 and indicates a flow of materials, products, commodities and cargo (collectively called "goods") from the supplier (inbound) side to the customer (outbound) side.

Raw materials are sourced and enter the supply chain on the inbound side and finished products or services exit the supply chain on the outbound side, with goods moving through the supply chain from origin to destination and information moving both forward and backwards through the supply chain. Reverse logistics moves upstream and includes goods returned, value carriers returned (such as pallets and empty gas bottles), disposal of assets, recycling materials, packaging materials and waste.

Transport plays an important part throughout the supply chain and from a simplified perspective, starts with bulk transport modes such as rail and sea on the inbound side, breakbulk transport in large trucks in between the plant and distribution centre (DC) and different size road transport vehicles carrying goods in unitised format (pallets or cartons) on the outbound side to final destination.

The inbound side used to be called materials management (now supply management) and the outbound side physical distribution (now distribution management), while the two sides together is called logistics management. The logistics elements or functions active en route from origin to destination include:

- Transport;

- Warehousing;

- Inventory management;

- Procurement;

- Customer service;

- Materials handling;

- Reverse logistics;

- Order management;

- Packaging;

- Freight forwarding; and

- Information systems.

Supply chain management on the other hand, implies the integration of all the mentioned elements or functions from origin to destination to provide for the management of a coherent sequence of activities from the suppliers of your suppliers to the customers of your customers and eventually to the consumers in the case of consumable products. This implies that a number of individual supply chains as indicated in Fig. 1 are all being integrated and interlinked into a complex network of demand and supply that requires very special management skills. 


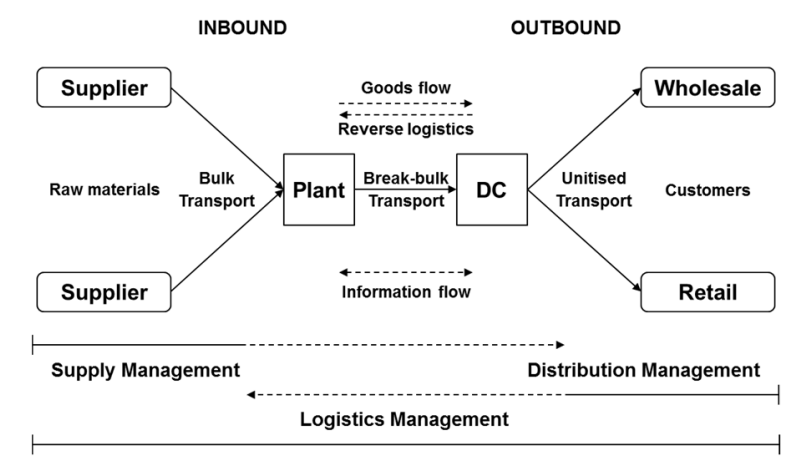

Figure 1: Logistics management (adapted from De Villiers et al. [4]).

Christopher [5] discusses the future requirement for structural flexibility in this complex environment and suggests that as supply chains become more 'virtual' than 'vertical', there will be a growing need for network orchestration. The ability to structure appropriate networks and to synchronise the activities across the nodes and links of those networks will be paramount in the era of network competition.

\section{PLANNING HIERARCHY}

Stock and Lambert [6] use the planning hierarchy (originally developed by Copacino of Andersen Consulting in 2000) very effectively to develop a strategic logistics plan. Fig. 2 provides an adapted version of this planning hierarchy to include inter alia procurement as well as freight forwarding on the functional level, plus some minor editing to expand description of some of the key areas.

Planning should start at the strategic level, and follows in a specific order through the structural, functional and operational levels as indicated by the arrow, to ensure structure follows strategy. Conceptual issues are addressed at the strategic and structural levels, with an overlap into the functional level, while detail issues receive attention on the functional and operational levels. Assumptions are allowed on conceptual level where less accuracy is needed but calculations made on the detail level need to be more accurate.

\section{SCOPE DEFINITION}

\section{DECISION LEVELS}

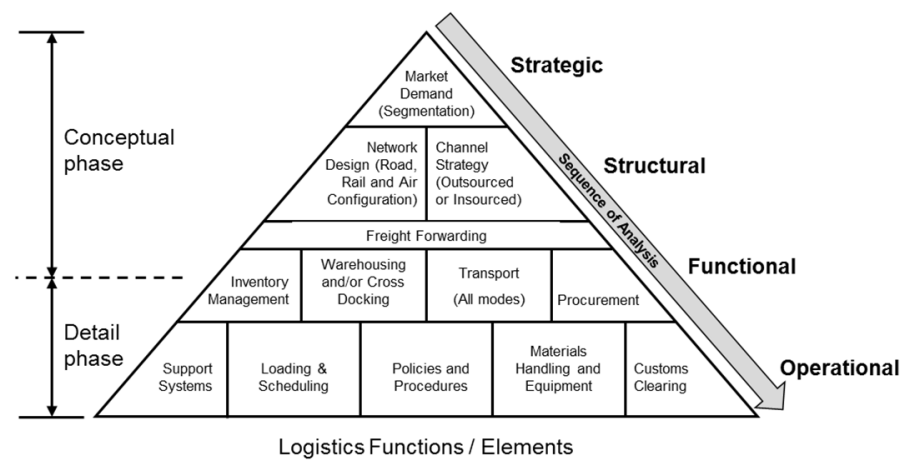

PLANNING FRAMEWORK

Figure 2: Planning hierarchy (adapted from Stock and Lambert [6]). 
The pinnacle of the triangle or hierarchy starts with the specific requirements of the customer, based on an analysis of the market demand in specific segments as well as the anticipated growth in demand. Once the demand is determined and future growth estimated, the planning process should proceed to network design and channel strategy on structural level.

Network design addresses questions such as the number and location of facilities (including plants, distribution centres, warehouses, depots and terminals) and centralisation versus decentralisation while channel strategy refers to roles and responsibilities of stakeholders and strategies such as outsourcing, insourcing and combinations thereof. Once the network design and channel strategy are done, planning moves to the functional level where more detail of the respective logistics elements or functions such as inventory management, warehousing, transport and procurement are addressed. This includes inventory replenishment strategies, warehouse automation, transport mode and type selection and centralised versus decentralised purchasing.

Once the functionality of the elements are known, specific design of support systems, loading and scheduling technology, policies and procedures, materials handling and customs procedures can be addressed on operational level.

So, as example, one can only address racking and shelving (materials handling and equipment) once the warehouse design has been done, after the decisions were made regarding centralised or decentralised warehousing on structural level (network design), which can only be done once demand has been confirmed on strategic level.

The importance of the planning hierarchy should not be underestimated as it provides a very useful framework for strategic planning in general, and transportation planning in particular.

\section{DISTRIBUTION CHANNEL}

Distribution management was defined in Fig. 1 as the outbound side mainly from the DC to the customer, although sometimes the link from the plant to the DC is included. Distribution includes both transport and warehousing and distribution channels refer to the path that the goods travel outbound to final destination. Some of the various options for this path are provided in Fig. 3.

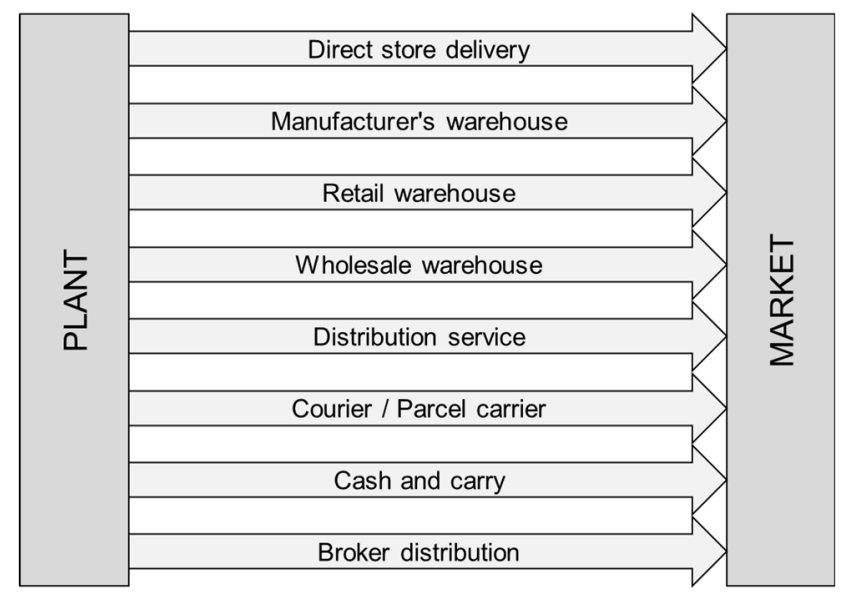

Figure 3: Alternative distribution channels (adapted from Rushton et al. [7]). 
Each of the respective distribution channels demands specific design criteria for activities such as:

- Inventory management (such as cycle stock and safety stock levels);

- Replenishment strategy (such as period review and min-max levels);

- Warehousing (such as centralisation versus decentralisation);

- Load and drop sizes;

- Transport mode and type;

- Fleet type and size;

- Outsourcing versus insourcing for various functions; and

- Service levels.

The choice of distribution channel is further impacted by the characteristics of goods handled in the channel as well as the format of handling. Dry bulks is different from liquid bulk; break-bulk in containers or on pallets require completely different handling and the cold chain for chilled or frozen goods has very specific and expensive requirements to ensure integrity of temperature along the distribution channel.

Rushton et al. [7] are of the opinion that channel objectives will necessarily differ from company to company but is it important to intentionally agree on the objectives as the design of the distribution channel is directly linked to the objectives. In addition to the objective of maintaining the cold chain intact as mentioned, they suggest the following possible objectives:

- To make the product readily available to the market at which it is aimed;

- To enhance the prospect of sales being made;

- To achieve cooperation with regard to any relevant distribution factors;

- To achieve a given level of service;

- To minimise logistics and total costs; and

- To receive fast and accurate feedback of information.

Fig. 4 provides an indication of alternative options for conventional fresh fruit distribution channels when exporting through a deep-sea port to foreign markets. The options include various combinations of ambient and refrigerated transport, accumulating buffer stock at the port in anticipation of the arrival of the vessel, different cooling options from cooling at a centralised facility to cooling at decentralised depots, and finally loading options at the port en route to the market.

Similar options exist for the export of fresh fruit in containers and that is shown in Fig. 5. The location of stuffing the containers (packing the pallets into the containers) can be at a centralised facility, at decentralise depots or at the port. Latest trends favour containerisation to most developed countries where ports are designed for container handling and no breakbulk or palletised goods will be handled, but this is not the case in developing countries where various ports in Africa, as example, prefer labour-intensive handling. This is due to a lack of suitable container handling equipment or where affordable manual labour is available.

In both examples of conventional and containerised handling, the alternative distribution channels show the option of a centralised facility at the centre of gravity (CoG). This will be discussed in detail in Section 7 but the role of intermediaries such as this centralised facility requires some attention before we move on.

Lambert and Stock [8] provide a practical example of how intermediaries can reduce the cost of contact between supplier and customer. In the case of direct distribution from four suppliers to ten customers, the contacts are $4 \times 10$ or 40 contacts in total. This is shown in Fig. 6. 


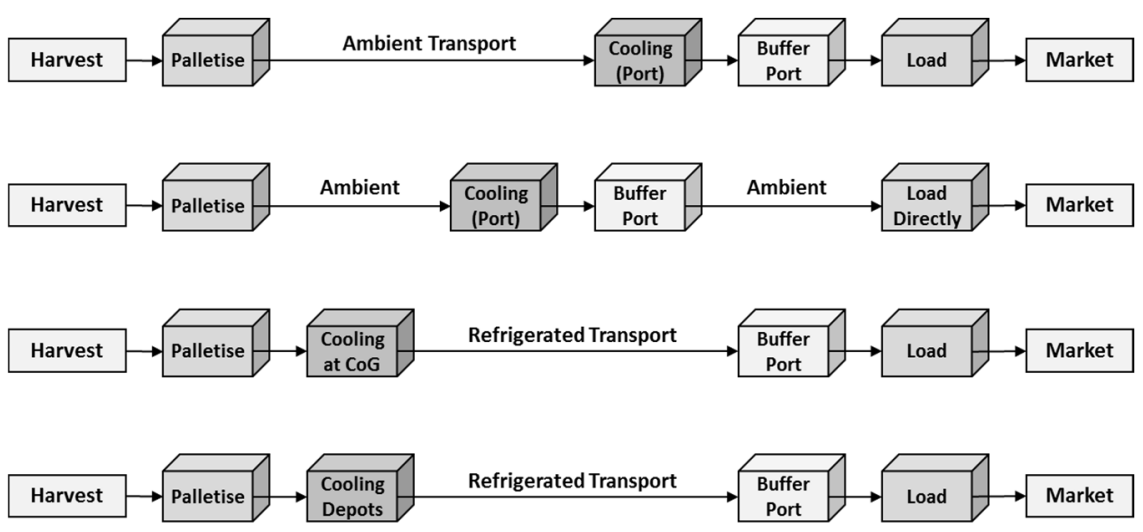

Figure 4: Conventional fresh fruit distribution channels.

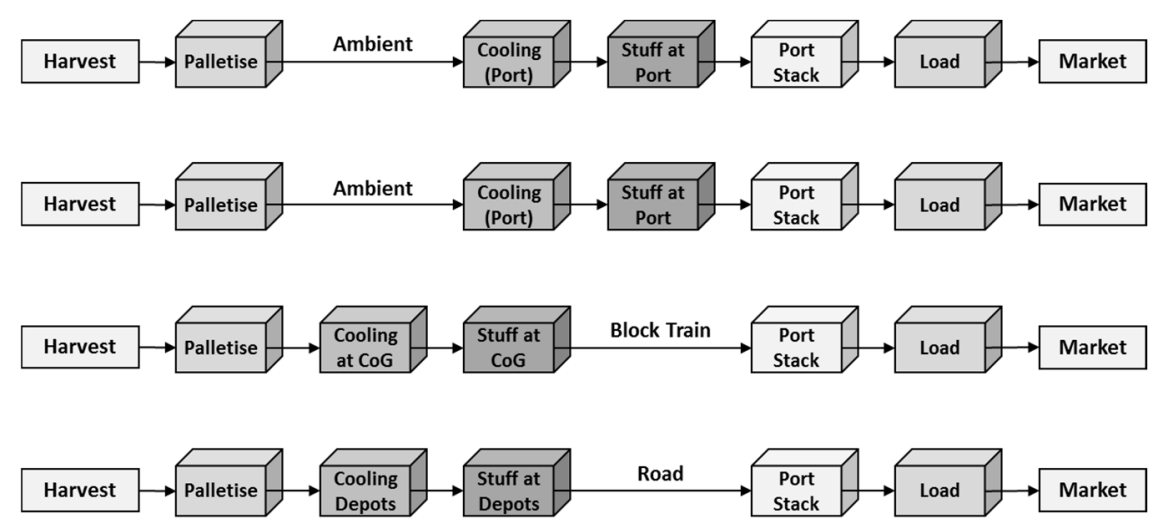

Figure 5: Containerised fresh fruit distribution channels.

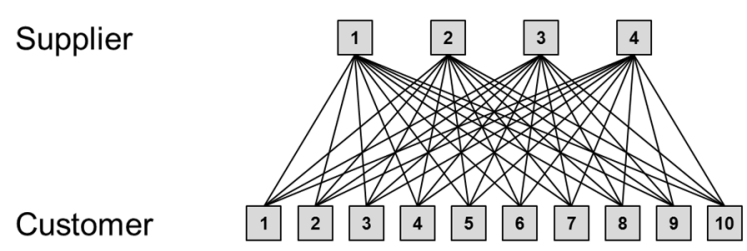

Figure 6: Direct distribution (40 contacts) [8].

However, in the case of distribution through an intermediary from four suppliers to ten customers, the contacts are $4+10$ or 14 contacts in total, as shown in Fig. 7. This is significant less than the 40 contacts in direct distribution and provides much less interruption along the channel. 


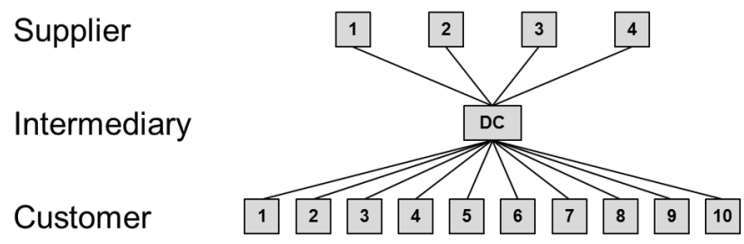

Figure 7: Distribution through intermediary (14 contacts) [8].

The role of intermediaries depends on the specific logistics function and could include managing a warehouse or distribution centre as shown in the figures or it could be taking responsibility for transport. This is called outsourcing and implies a third party moves in between the supplier (first party) and the customer (second party), as shown in Fig. 8. The first party is usually the seller, the second party is the buyer and the third party is the service provider in the middle. The third party is called a "third-party logistics service provider" (3PL) and operates on behalf of either the supplier or the customer.

Industry experience has confirmed that unfortunately not all customers are satisfied with the 3PL services due to some sub-optimal rendering of services which could have been integrated and offered at lower cost to the supply chain. An example could be the export of chemicals by one company and the import of chemicals by another. Often the two companies are served by two service providers while the liquid bulk carriers should rather be optimised with the same vehicles used for the export and imports, preventing empty trucks and full trucks to pass each other on the same route and in the same channel.

This has caused some companies to reconsider outsourcing and rather bring the fleet back in-house (insourcing) to be able to manage the function more optimal in house. Gattorna [10] introduces the concept of "fourth-party logistics service provider" (4PL) as a possible solution that incorporates the advantages of both outsourcing and insourcing. A new entity is established to manage multiple 3PL service providers as indicated in Fig. 9, to achieve much better integration and improved service delivery at much lower cost.

According to Gattorna [10], the 4PL functions as "an integrator that assembles the resources, capabilities and technology of its own organisation and other organisations to design, build and run comprehensive supply chain solutions and which have the cultural sensitivity, political and communication skills, and the commercial acumen, not only to find value, but to create motivating and sustainable deals that offer incentives to all parties involved".

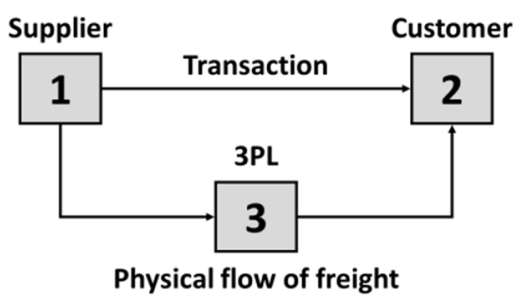

Figure 8: Third-party logistics (3PL) [9]. 


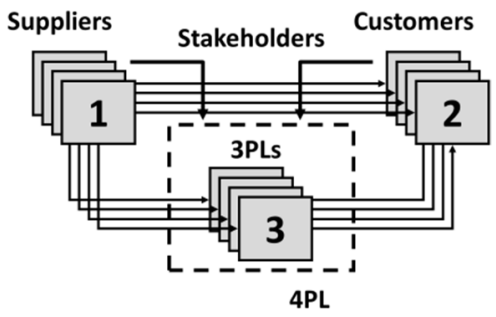

Figure 9: Fourth-party logistics (4PL) [9].

In essence, this means a solution that incorporates the advantages of both outsourcing and insourcing to provide maximum overall benefit. It differs from traditional 3PL arrangements in four main respects:

- The 4PL organisation is often a separate entity established as a Joint Venture (JV) or long-term contract between a primary client and one or more partners;

- It acts as a single interface between the client and multiple logistics service providers;

- All aspects of the client's supply chain are managed by the 4PL organisation; and

- It is also possible for a major third-party logistics provider to form a 4PL organisation within its existing structure.

The 4PL concept addresses the shortfalls of traditional 3PL arrangements and offers the opportunity to achieve substantial incremental benefits. In addition, the concept can be extended to an existing 3PL, converting it into a 4PL.

\section{LOCATION ANALYSIS}

Stock and Lambert [11] provide a useful overview on how to determine the best place for a warehouse and they suggest the following three general locations from a macro perspective:

- $\quad$ market positioned warehouse;

- $\quad$ production positioned warehouse; and

- intermediately positioned warehouse.

The first option of market positioned, locating the facility closest to the final customer, should be considered for service sensitive distribution channels and where close proximity to the customer is crucial. This is also true for the location of a production facility (or plant) for "weight-gaining" goods such as bottling of beverages. The second option of production positioned, locating the facility close to the sources of supply or production function, should be considered for perishable products where considerations other than customer service are important. This also applies to "weight-losing" goods such as iron ore converted into steel. The third location is obviously a hybrid of the first two and will be determined by trade-offs between service and cost.

The authors continue with a discussion on macro considerations and they include reference to the most relevant location theories of the following economic geographers:

1. Johann Von Thunen, a German agriculturist, suggested that transport cost minimisation was the most important locational determinant. Agricultural production would take place where the farmer would maximise profits and as locations further 
from the city (market) would incur greater transportation cost, low-value products should be produced near the city.

2. Alfred Weber, a German economist, developed a theory for the location of industrial production facilities. He assumed equally accessible transportation and constant transportation costs with respect to weight and distance, and defined the optimum location as the point that represents the least-cost location. More specifically, the least-cost site is the location that minimises total transportation costs; for both raw materials and finished goods to the market.

3. Edgar Hoover, an American theorist, investigated the optimum location of industrial facilities based on cost factors, including demand factors of the market area after a firm determines a location. He considered transportation costs, agglomerative factors and industrial costs. His analysis was based on the fact that transport costs are not linear with respect to distance.

4. Melvin Greenhut expanded on the work of the three mentioned geographers and included environmental and security factors as well as profitability elements in the location choice. He suggests the optimal facility location to be where profits are maximised.

Ackerman [12] suggests that once the macro analysis provided a suitable region, attention should be given to the micro level factors and he recommends the checklist of questions indicated in Table 1.

The list of questions seems daunting but it is important that the location analysis is done properly from the start to prevent surprises and expensive requirements for compliance once the project started. It might be a good idea to do the location analysis (both macro and micro level) on a reasonably high level to allow further refinements once the logistics network design has been done and the centre of gravity located. This implies an iterative process that will yield the best results and highest possibility of choosing the most optimal site.

\section{LOGISTICS NETWORK DESIGN}

Logistics network design follows in the planning hierarchy directly behind market demand and segmentation and after looking at macro level at possible regions for the development of one centralised distribution centre or a network of facilities for decentralised distribution.

Simchi-Levi et al. [13] suggest that network design determines the physical configuration and infrastructure of the supply chain. This is a strategic decision that has long-lasting effect on the firm and involves typical decisions related to plant and warehouse location as well as distribution and sourcing. The objective is to design or configure the logistics network to minimise production costs, purchasing costs, inventory holding costs, facility costs and transportation costs. The authors are of the opinion that the trade-offs are clear and explains that increasing the number of warehouses typically yields:

- An improvement in service level due to a reduction in average travel time to the customers;

- An increase in inventory costs due to increased safety stocks required to protect each warehouse against uncertainties in customer demands;

- An increase in overhead and setup costs;

- A reduction in outbound transportation costs (from warehouses to customers); and

- An increase in inbound transportation costs (from the suppliers and/or manufacturers to the warehouses). 
Table 1: Check list to locate your next warehouse (adapted from Ackerman [12]).

\begin{tabular}{|c|c|}
\hline Category & Question \\
\hline $\begin{array}{l}\text { Government } \\
\text { restrictions }\end{array}$ & $\begin{array}{l}\text { 1) Is the property properly zoned for warehousing or possible future uses? } \\
\text { 2) Are there limits or restrictions on parking? } \\
\text { 3) What is the maximum expansion capability? } \\
\text { 4) Does the property have any easements or protective covenants? } \\
\text { 5) Do access roads have any restrictive load limits? }\end{array}$ \\
\hline $\begin{array}{l}\text { Geographic } \\
\text { restrictions }\end{array}$ & $\begin{array}{l}\text { 1) It the grade too steep for construction? } \\
\text { 2) Are there drainage problems? } \\
\text { 3) Are there streams or wetlands near the site? } \\
\text { 4) Where is the } 100 \text {-year floodplain? } \\
\text { 5) Do have geodetic survey information on seismic fault lines? } \\
\text { 6) Has the site be used for landfill and is there landfill debris on the site? } \\
\text { 7) What is the load bearing capacity of the soil? } \\
\text { 8) Are there restrictions on vegetation removal? } \\
\text { 9) Are there any environmental fatal flaws on the site? }\end{array}$ \\
\hline Transportation & $\begin{array}{l}\text { 1) What is the access to the nearest highway interchange? } \\
\text { 2) What is the distance from road freight terminals? } \\
\text { 3) Have we interviewed road freight managers about this site? } \\
\text { 4) What is the cartage cost to the closest inland container terminal? } \\
\text { 5) What is the cartage cost to the closest maritime container terminal? } \\
\text { 6) What is the cartage cost to the closest air freight terminals? } \\
\text { 7) Is the site convenient for pickups by our most important customers? }\end{array}$ \\
\hline \begin{tabular}{|l|} 
Utilities \\
\end{tabular} & $\begin{array}{l}\text { 1) What is the source of water supply? } \\
\text { 2) Is the volume and pressure of water sufficient to support an early suppression fast response } \\
\text { (ESFR) sprinkler system? } \\
\text { 3) What is the electric power supply? } \\
\text { 4) Is it possible to install alternative energy technology to mitigate power interruptions? } \\
\text { 5) Have we received recent utility bills? } \\
\text { 6) What incentives are available from the electric utility supplier? } \\
\text { 7) Is natural gas available? } \\
\text { 8) Is sub-metering or prepaid electric and gas permitted? } \\
\text { 9) Are there any limitations on utility capacity or demand? }\end{array}$ \\
\hline Security & $\begin{array}{l}\text { 1) Does the sprinkler system meet preferred risk standards? } \\
\text { 2) Is there a secondary water source for the sprinkler system? } \\
\text { 3) Have you obtained recent insurance inspection reports? } \\
\text { 4) Have you interviewed law enforcement officials? } \\
\text { 5) Have you interviewed managers of neighbouring facilities? } \\
\text { 6) Are armed response services available? }\end{array}$ \\
\hline Labour & $\begin{array}{l}\text { 1) Are nearby businesses unionised? } \\
\text { 2) What is the community's attitude towards trade unions? } \\
\text { 3) Is there a labour shortage or high unemployment? } \\
\text { 4) What is the quality rating of nearby schools? }\end{array}$ \\
\hline Community & $\begin{array}{l}\text { 1) Do local civic leaders welcome industrial expansion? } \\
\text { 2) Is there any opposition to warehouse operations? } \\
\text { 3) Is there a history of difficulty in rezoning? }\end{array}$ \\
\hline Taxation & $\begin{array}{l}\text { 1) Have you obtained the most recent property appraisal? } \\
\text { 2) Have you analysed real estate tax history over the past } 10 \text { years? } \\
\text { 3) Have there been any recent tax assessments? } \\
\text { 4) Are there any tax abatement programs available? } \\
\text { 5) Is the location in a duty-free or enterprise zone (Industrial Development Zone or Special } \\
\text { Economic Zone)? } \\
\text { 6) Have you obtained the plans for any public improvements? } \\
\text { 7) How do inventory tax levels compare with other sites? } \\
\text { 8) Have you obtained all of the appropriate tax rate information? }\end{array}$ \\
\hline $\begin{array}{l}\text { New } \\
\text { construction }\end{array}$ & $\begin{array}{l}\text { 1) Have soil tests be done? (Geotechnical fatal flaw analysis) } \\
\text { 2) Are their landscaping requirements? } \\
\text { 3) Have you done an Environmental Impact Assessment? } \\
\text { 4) What are the estimated costs and time requirements for permits and development approval? }\end{array}$ \\
\hline
\end{tabular}


It is clear that the answer lies in total logistics costs, and not individual transport, warehousing or inventory costs. This will be discussed in more detail in Section 9 but suffice it to say that Blanchard [14] calls this "striking the proper balance". He quotes Harmelink as saying that "the objective of strategic network planning is to come up with the most economical way to ship and receive products while maintaining or increasing customer satisfaction requirements; simply put, a plan to maximise profits and optimise service".

The alternative different distribution channels as shown in Fig. 3 assume the existence of distribution centres, warehouses and or depots, collectively referred to as storage facilities (or nodes in the links between origin and destination). These facilities are important components of any logistics system and most channel strategies rely on some intermediate break-bulk and storage facility between producer and retailer or consumer.

Blanchard [14] lists a number of questions to be answered in developing a suitable network, and Table 2 links the questions to the specific level of the planning hierarchy as discussed in Section 3. It is clear that the questions are relevant at and should be addressed on a number of the levels in the planning hierarchy.

In conclusion, Simchi-Levi et al. [15] suggest that typically three distinct outbound distribution strategies (or network design options) are used:

- Direct shipment with items shipped directly from the supplier to the retail stores without going through distribution centres;

- Warehousing as the classical strategy in which warehouses keep stock and provide customers with items as required; and

- Cross docking where items are distributed continuously from suppliers through warehouses to customers. However, the warehouses rarely keep the items for more than 10 to 15 hours.

The choice between those options (and others) can be very complicated, with detail analyses required to establish the cost trade-offs, as well as quantitative techniques to determine storage facility location. There might not necessarily be one best solution but an integrated system of nodes and links (facilities and channels) in the logistics network.

One technique for solving the complicated choice is centre-of-gravity analysis, which is probably the most powerful tool for designing a new network from the basis of a "clean slate'. It enables an objective assessment of the actual centres of demand and supply, as well as of the combined position of both supply and demand. This will be discussed in the next section.

Table 2: Network design questions.

\begin{tabular}{|l|l|}
\hline Question & Planning hierarchy level \\
\hline 1) How many distribution centres (DCs) do you need? & Structural level \\
\hline 2) Where should the DCs be located? & Structural level \\
\hline 3) How much inventory should be stocked at each DC? & Functional level \\
\hline 4) Which customers should be serviced by each DC? & $\begin{array}{l}\text { Structural and functional } \\
\text { level }\end{array}$ \\
\hline 5) How should customers order from the DC? & Operational level \\
\hline 6) How should the DCs order from the suppliers? & Operational level \\
\hline 7) How often should shipments be made to each customer? & $\begin{array}{l}\text { Functional and operational } \\
\text { level }\end{array}$ \\
\hline 8) What should the service levels be? & Strategic level \\
\hline 9) Which transportation methods should be used? & Functional level \\
\hline
\end{tabular}




\section{CENTRE-OF-GRAVITY ANALYSIS TECHNIQUE}

The design of a suitable logistics network and the development of appropriate channel strategies in multiple markets and multiple suppliers is a daunting task and some modelling is needed to assist with the complex calculations. Coyle et al. [16] calls centre-of-gravity analysis the "grid technique" and suggest that to be a useful, simplistic heuristic modelling approach for determining the least-cost facility location. This modelling can easily be done by spreadsheets and does not require dedicated optimisation software.

Centre-of-gravity analysis is used to determine the least-cost location of a fixed facility (plant, distribution centre, warehouse, depot or terminal) for moving raw materials and finished goods in the network. The technique assumes sources of raw materials and markets are fixed and that supply and demand are known. The coordinates of each supply and demand point are needed to present the points in geographical format on a map and to calculate the transport costs of all movements.

The technique is shown graphically in Fig. 10. If all the points are plotted at their respective coordinates on a map and respective supply or demand volumes (represented by weights) are connected through small holes to a central ring on the surface, the ring will come to rest in the centre of gravity.

The analysis is based on the differential transport costs of raw materials from the production or manufacturing facilities or suppliers to one or more fixed facility such as distribution centres (primary transport), and finished goods from these facilities directly to destinations in the market, such as retail outlets (secondary transport). The result of the analysis provides a theoretical indication of the least cost location of the centralised facility.

Bowersox and Closs [17] provide four analytical techniques for calculating the centre or gravity:

- Ton-centre solution (weight-centre solution);

- Mile-centre solution (distance-centre solution);

- Ton-mile-centre solution (weight-distance-centre solution); and

- Time-ton-mile-centre solution (time-weight-distance-centre solution).

The ton-centre solution (weight-centre solution) is the basic centre-of-gravity calculation and the centre of movement represents the least cost location. The mathematical formula is presented in eqn (1).

where:

$$
x=\frac{\sum_{i=1}^{n} x_{i} F_{i}}{\sum_{i=1}^{n} F_{i}}, \quad y=\frac{\sum_{i=1}^{n} y_{i} F_{i}}{\sum_{i=1}^{n} F_{i}}
$$

$x, y=$ Coordinates for the centre of gravity

$x_{i}, y_{i}=$ Coordinates for all origins and destinations

$F_{i} \quad=$ Supply or demand (ton)

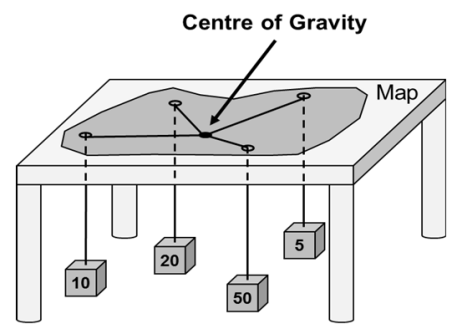

Figure 10: Centre-of-gravity technique. 
The mile-centre solution (distance-centre solution) determines the geographical point that minimises the combined distance to all points.

The ton-mile and time-ton-mile-centre solutions reflect most accurately reality and should be used where possible. It can incorporate a number of variables that needs to be considered, such as transport rates (Rand/ton.km) which is different for primary and secondary transport.

Similarly, a differential parameter for congestion in urban areas that reflects the additional time required, can be used. This parameter could range from high value for high congestion to a low factor for low congestion. The mathematical formula of a hybrid between the two solutions (adapted from Bowersox and Closs [17]) is shown in eqn (2).

$$
x_{k}=\frac{\sum_{i=1}^{n} x_{i} F_{i} R_{i} C_{i} / d_{i}}{\sum_{i=1}^{n} F_{i} R_{i} C_{i} / d_{i}}, y_{k}=\frac{\sum_{i=1}^{n} y_{i} F_{i} R_{i} C_{i} / d_{i}}{\sum_{i=1}^{n} F_{i} R_{i} C_{i} / d_{i}},
$$

where:

$$
\begin{array}{ll}
x_{k}, y_{k} & =\text { Coordinates for iteration } k \text { (in } \mathrm{km}) \\
x_{i}, y_{i} & =\text { Coordinates for all origins and destinations (in } \mathrm{km}) \\
F_{i} & =\text { Supply or demand (ton) } \\
R_{i} & =\text { Transport rate }(\mathrm{R} / \text { ton. } \mathrm{km}) \\
C_{i} & =\text { Congestion factor (Relative value) } \\
d_{i} & =\text { Distance between points for each iteration }
\end{array}
$$

This calculation requires an iterative process to determine the increasingly improved location, based on the least cost of transport. The distance between the locations, with each iteration reduces every time a better location is found and the objective is to found the spot where the costs are lowest. The measurement of distance between two points is done by the formula in eqn (3):

$$
d_{i}=\sqrt{\left(x_{i}-x_{k}\right)^{2}+\left(y_{i}-y_{k}\right)^{2}}
$$

where:

$$
\begin{array}{ll}
x_{k}, y_{k} & =\text { Coordinates for iteration } k(\text { in } \mathrm{km}) \\
x_{i}, y_{i} & =\text { Coordinates for all origins and destinations (in } \mathrm{km}) \\
d_{i} & =\text { Distance between points for each iteration }
\end{array}
$$

The calculations are relatively easily done by spreadsheets and are shown in tabular and graphical format in an example in the next section.

\section{CENTRE-OF-GRAVITY ANALYSIS EXAMPLE}

The application of the centre-of-gravity technique can be shown in the following hypothetical example; where the purpose is to determine the least-cost location of a new distribution centre.

The market consists of five customer destinations located in five different areas, with the weekly demand at each customer location as follows:

- Customer 1: 20-ton product

- Customer 2: 10-ton product

- Customer 3: 15-ton product

- Customer 4: 5-ton product

- Customer 5: 12-ton product 
The supply to the market consists of two local suppliers and two foreign suppliers from where imports are received by air and by sea from the following four origins:

- Supplier 1: 11-ton product

- Supplier 2: 11-ton product

- Imports by sea: 20-ton product

- Imports by air: 20-ton product

Inbound (primary) transport from the local suppliers, the airport and the sea port is done by 20 ton trucks at a rate of R 0.60 per ton.km while outbound (secondary) transport or delivery to the customers is done by 8 ton trucks at a rate of $\mathrm{R} 1.20$ per ton.km.

This information is presented in Table 3 with the respective calculations. The known values include volume (in ton) supply or demand at each origin and destination as well as the respective transport rates (in Rand/ton. $\mathrm{km}$ ). The centres of gravity are consequently calculated for the demand centre of gravity, supply centre of gravity as well as the combined centre of gravity.

Optimisation of the location is done by an iterative process where new coordinates for the best location is calculated by sequential iterations until the difference becomes marginal. The optimisation iteration process of 15 iterations is shown in Table 4 and the final location also presented in Table 3.

The results of the calculations done in the two tables are provided graphically in Fig. 11.

The locations of the customers are indicated with circles, the location of the supply points with blocks and the location of the centres of gravity with diamonds. The supply centre of gravity is located closer to the airport and seaport where most products originate and the demand centre of gravity is somewhere in the middle of the market.

The combined centre of gravity is located on a straight line between the supply and demand centres of gravity, but clearly much closer to the demand side, due to the higher cost of transport used for secondary transport or delivery to the market. The optimised location moves slightly lower in the graph towards the supply centre of gravity. The ideal location for a distribution centre is consequently at this optimised position.

Table 3: Centre-of-gravity calculations.

\begin{tabular}{|c|c|c|c|c|c|c|c|c|c|c|c|c|}
\hline Location & \begin{tabular}{|l}
$X$ \\
$(\mathrm{~km})$
\end{tabular} & \begin{tabular}{|l}
$\mathbf{Y}$ \\
$(\mathrm{km})$ \\
\end{tabular} & \begin{tabular}{|l}
$\mathbf{F}$ \\
(ton)
\end{tabular} & $\mathbf{R}(\mathrm{R} /$ ton.km) & $\mathbf{F} \times \mathbf{R}$ & $\mathbf{X} \times \mathbf{F} \times \mathbf{R}$ & $\mathbf{Y} \times \mathbf{F} \times \mathbf{R}$ & d (km) & Cost (R) & $\mathbf{F} \times \mathbf{R} / \mathbf{d}$ & $\mathbf{X} \times \mathbf{F} \times \mathbf{R} / \mathbf{d}$ & $\mathbf{Y} \times \mathbf{F} \times \mathbf{R} / \mathbf{d}$ \\
\hline Customer 1 & 38.00 & 42.00 & 20.0 & 1.20 & 24.0 & 912.0 & 1008.0 & 27.76 & \begin{tabular}{ll|}
$\mathrm{R}$ & 666.20 \\
\end{tabular} & 0.86 & 32.85 & 36.31 \\
\hline Customer 2 & 10.00 & 45.00 & 10.0 & 1.20 & 12.0 & 120.0 & 540.0 & 30.39 & R 364.71 & 0.39 & 3.95 & 17.77 \\
\hline Customer 3 & 22.00 & 10.00 & 15.0 & 1.20 & 18.0 & 396.0 & 180.0 & 8.27 & \begin{tabular}{ll|}
$\mathrm{R}$ & 148.93 \\
\end{tabular} & 2.18 & 47.86 & 21.76 \\
\hline Customer 4 & 15.00 & 39.00 & 5.0 & 1.20 & 6.0 & 90.0 & 234.0 & 22.82 & $\begin{array}{ll}\mathrm{R} & 136.95 \\
\end{array}$ & 0.26 & 3.94 & 10.25 \\
\hline \begin{tabular}{|l|} 
Customer 5 \\
\end{tabular} & 45.00 & 11.00 & 12.0 & 1.20 & 14.4 & 648.0 & 158.4 & 22.14 & $\begin{array}{|ll|}\mathrm{R} & 318.80 \\
\end{array}$ & 0.65 & 29.27 & 7.15 \\
\hline Supplier 1 & 10.00 & 20.00 & 11.0 & 0.60 & 6.6 & 66.0 & 132.0 & 14.14 & 93.35 & 0.47 & 4.67 & 9.33 \\
\hline Supplier 2 & 38.00 & 22.00 & 11.0 & 0.60 & 6.6 & 250.8 & 145.2 & 14.55 & 96.01 & 0.45 & 17.24 & 9.98 \\
\hline Sea port & 20.00 & 2.00 & 20.0 & 0.60 & 12.0 & 240.0 & 24.0 & 16.52 & $\begin{array}{|ll|}\mathrm{R} & 198.24 \\
\end{array}$ & 0.73 & 14.53 & 1.45 \\
\hline Airport & 10.00 & 10.00 & 20.0 & 0.60 & 12.0 & 120.0 & 120.0 & 16.14 & $\begin{array}{ll}\mathrm{R} & 193.72 \\
\end{array}$ & 0.74 & 7.43 & 7.43 \\
\hline Demand CoG & 29.11 & 28.50 & 62.0 & & & & & 11.65 & & & & \\
\hline Supply CoG & 18.19 & 11.32 & 62.0 & & & & & 8.87 & & & & \\
\hline $\begin{array}{l}\text { Combined } \\
\text { CoG }\end{array}$ & 25.47 & 22.77 & 124.0 & & & & & 4.97 & & & & \\
\hline $\begin{array}{l}\text { Optimised } \\
\text { CoG } \\
\end{array}$ & 24.00 & 18.02 & & & & & & 0.00 & & & & \\
\hline Total demand & & & & & 74.4 & 2166.0 & 2120.4 & & R 1635.59 & 4.3 & 117.9 & 93.2 \\
\hline Total supply & & & & & 37.2 & 676.8 & 421.2 & & $\mathrm{R} \quad 581.32$ & 2.4 & 43.9 & 28.2 \\
\hline $\begin{array}{l}\text { Total } \\
\text { combined }\end{array}$ & & & & & 111.6 & 2842.8 & 2541.6 & & R 2216.92 & 6.7 & 161.7 & 121.4 \\
\hline
\end{tabular}


Table 4: Centre-of-gravity optimisation iteration.

\begin{tabular}{|r|l|l|l|l|}
\hline Optimisation & $\mathbf{X ~ ( k m )}$ & $\mathbf{Y ~ ( k m )}$ & Cost (R) & $\mathbf{d ~ ( k m ) ~}$ \\
\hline Distance & 24.01 & 18.03 & R 2 216.92 & 0.00 \\
\hline Optimised CoG & 24.00 & 18.02 & & \\
\hline 0 & 25.47 & 22.77 & R 2 243.37 & 1.82 \\
\hline 1 & 25.20 & 20.97 & R 2 227.54 & 1.09 \\
\hline 2 & 24.88 & 19.93 & R 2 221.51 & 0.69 \\
\hline 3 & 24.61 & 19.29 & R 2 218.98 & 0.46 \\
\hline 4 & 24.42 & 18.87 & R 2 217.86 & 0.30 \\
\hline 5 & 24.28 & 18.60 & R 2 217.35 & 0.21 \\
\hline 6 & 24.19 & 18.41 & R 2 217.12 & 0.14 \\
\hline 7 & 24.13 & 18.29 & R 2 217.01 & 0.10 \\
\hline 8 & 24.09 & 18.20 & R 2 216.96 & 0.07 \\
\hline 9 & 24.06 & 18.14 & R 2 216.94 & 0.04 \\
\hline 10 & 24.04 & 18.10 & R 2 216.93 & 0.03 \\
\hline 11 & 24.03 & 18.08 & R 2 216.92 & 0.02 \\
\hline 12 & 24.02 & 18.06 & R 2 216.92 & 0.01 \\
\hline 13 & 24.01 & 18.04 & R 2 216.92 & 0.01 \\
\hline 14 & 24.01 & 18.03 & R 2 216.92 & 0.01 \\
\hline 15 & 24.01 & 18.03 & R 2 216.92 & 0.00 \\
\hline & & & & \\
\hline
\end{tabular}

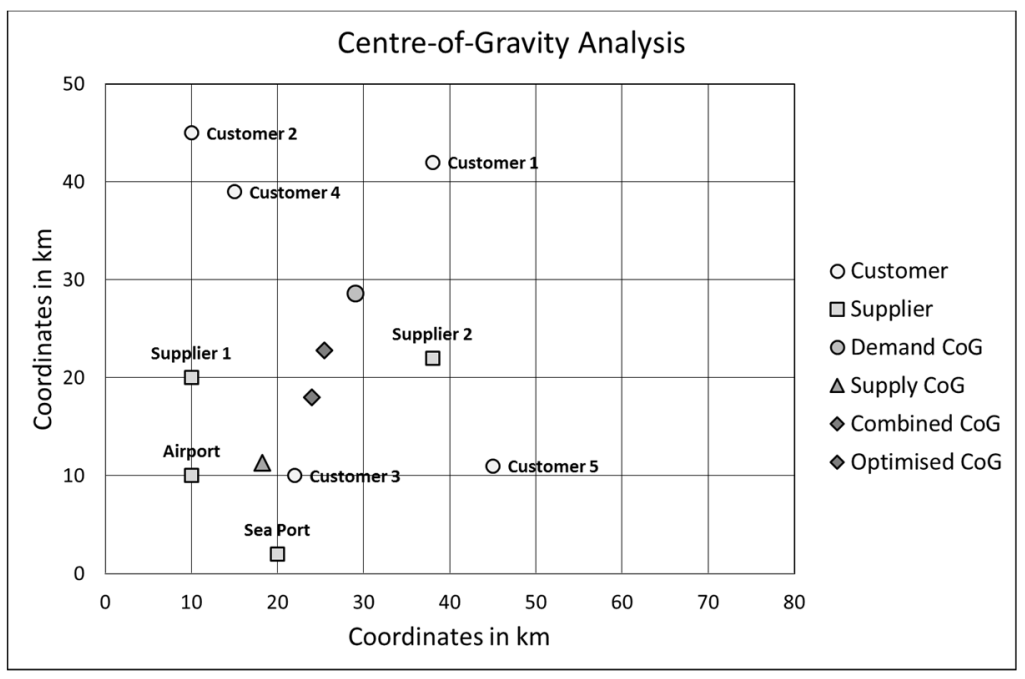

Figure 11: Centre-of-gravity analysis graph.

In conclusion, it is important to mention that the centres of gravity should not be regarded necessarily as the answer. It provides a good starting point on macro level of looking for the best location, but various qualitative factors on micro level such as listed in Table 1 should be considered, as well as the total logistics costs discussed in the next section.

\section{TOTAL LOGISTICS COSTS}

Once the location of the centres of gravity has been determined and alternative logistics networks configured accordingly, the individual cost components should be calculated for 
the logistics elements or functions to determine the total logistics costs. Rushton et al. [18] suggest that the following costs should be considered:

- Primary transport cost (inbound; supply from manufacturers or suppliers to distribution centres or other intermediaries);

- Secondary transport cost (outbound; delivery from distribution centres to the market);

- Warehousing cost (including capital and operational costs);

- Inventory holding costs (including capital, service and risk costs); and

- An information system costs (including order processing costs).

Other costs of less importance can include communication costs, protective packaging, direct and indirect taxation, cost of reverse logistics and procurement costs. These costs are usually relatively small but it is important to include those if the amounts are significant and can have a determining impact on the total logistics costs.

The analysis of the total logistics costs recognises that many more costs are incurred through the provision of availability than just transport and warehousing costs. The total least cost might not be where the transport cost is minimum or where inventory or information costs are minimum. Managing transportation, inventories and order processing activities collectively could lead to substantial cost reduction when compared with managing the functions in isolation.

In practice, primary transport, secondary transport, warehousing and inventory holding costs are most important and should be considered. Most of the costs are relatively easily available and where not, industry averages can be used, but in an effort to simplify the process, the analysis should be done by comparing relative rather than absolute numbers. The result of the comparison is the same, but the effort in only considering those cost elements that differ in the different alternatives, rather than a zero-based activity based costing exercise, is significantly less.

The relative relationship between the mentioned costs components are shown in Fig. 12. It is clear that there are significant trade-offs between the different components, such as between secondary transport and warehousing costs. The transport manager will definitely choose decentralisation with multiple depots to be closer to the market and travel less distance

\section{Total Logistics Costs}

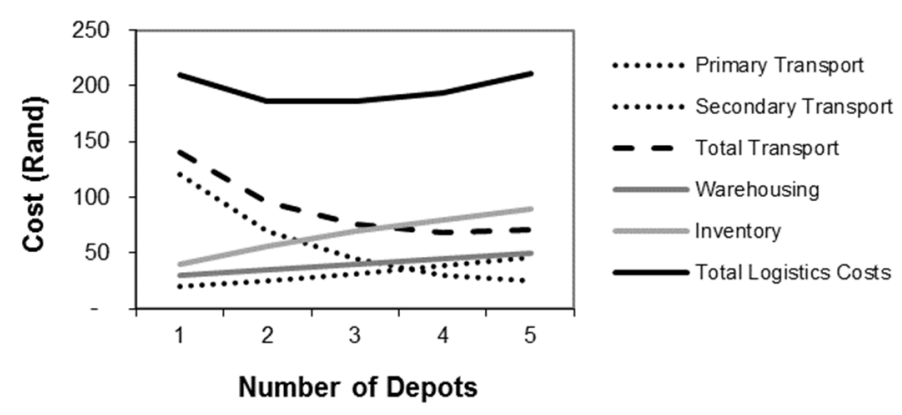

Figure 12: Total logistics costs. 
while the warehouses manage will choose centralisation due to obvious cost savings. The answer lies in the total costs and hence the importance to make decision based on total logistics costs and not the individual components.

In conclusion, although the total logistics costs provide a clear quantitative result, other qualitative factors such as service levels, corporate strategy and corporate social responsibility should also be considered before a final choice is made. However, total logistics costs should probably be the most important and relevant performance indicator in the choice of a suitable logistics network.

So, centre-of-gravity analysis provides the answer to where the facilities should be located while total logistics costs provides the answer to how many facilities should be operated. This leads into the last part of the chapter that covers the development of the most appropriate channel strategy.

\section{CHANNEL STRATEGIES}

Once the ideal logistics network has been identified, based on centre-of-gravity analysis on macro level and total logistics costs have been calculated to assist with micro level comparison, the most appropriate channel strategy should be developed.

There are various approaches to address the development of this strategy, but the supply chain design (or channel strategy) process consists according to Stock and Lambert [19] of the following steps:

1. Establish supply chain objectives.

2. Formulate a supply chain strategy.

3. Determine supply chain structure alternatives.

4. Evaluate supply chain structure alternatives.

5. Select supply chain structure.

6. Determine alternatives for individual supply chain members.

7. Evaluate and select individual supply chain members.

8. Measure and evaluate supply chain performance.

9. Evaluate supply chain alternatives when performance objectives are not met or when attractive new options become available.

The second step suggests that a supply chain strategy be formulated and Perez [20] submits that supply chain strategies generally conform to one of six types as indicated in Table 5 .

This is similar to work done by Gattorna [21] over many years on the development of channel strategies. He is of the opinion that there exist the following generic supply chain types:

- Continuous replenishment supply chain: Very predictable demand from known customers; easily managed through tight collaboration with these collaborative customers; focus on retention of customer relationships;

- Lean supply chain: Regular pattern of demand; quite predictable and forecastable although may be seasonable; tend to be mature low risk products/services; focus on efficiency;

- Agile supply chain: Usually unplanned at least until the last possible moment. May result from promotions; new product launches; fashion marketing; unplanned stockouts; or unforeseen opportunities. Focus on the service-cost equation; and

- Fully flexible supply chain: Unplanned and unplannable demand due to unknown customers with exceptional, sometimes emergency, requests. Focus on providing creative solutions at a premium price. 
Table 5: Generic supply chain models [20].

\begin{tabular}{|c|c|c|}
\hline Orientation & $\begin{array}{c}\begin{array}{c}\text { Supply chain } \\
\text { model }\end{array} \\
\end{array}$ & Description \\
\hline \multirow{3}{*}{ 冚 } & 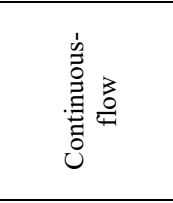 & $\begin{array}{l}\text { A supply chain focused on building synergies supported by collaborative } \\
\text { relationships. Low working capital for customers is the main deliverable. } \\
\text { Workload is smoothed by customer's demand. Order penetration point is } \\
\text { "make to stock" in order to ensure medium-high utilisation rates with a } \\
\text { high level of perfect orders. Production, driven by market demand, is } \\
\text { designed to replenish predefined inventory levels. }\end{array}$ \\
\hline & 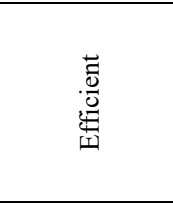 & $\begin{array}{l}\text { A supply chain focused on lowest cost. Used for functional and } \\
\text { commoditised products. Weakest value proposal when used in an isolated } \\
\text { way, useful when used as a backbone for supporting mixed strategies. } \\
\text { Efficiency is supported by a high asset utilisation rate based on "make to } \\
\text { forecast" model in order to maintain continuous production and ensure an } \\
\text { optimal production sequence, thereby reducing setup time. }\end{array}$ \\
\hline & 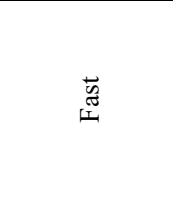 & $\begin{array}{l}\text { A supply chain focused on competitive cost and continuous portfolio } \\
\text { renewal. Short time from "idea to market" and an affordable cost are main } \\
\text { deliverables. Used for functional and short-lifecycle products oriented to } \\
\text { fashion. Demand is "pushed" by a collection forecast. Fast product } \\
\text { development is critical capability. Applied by "fashion creators", } \\
\text { especially in industries such as apparel and beauty products. }\end{array}$ \\
\hline \multirow{3}{*}{ 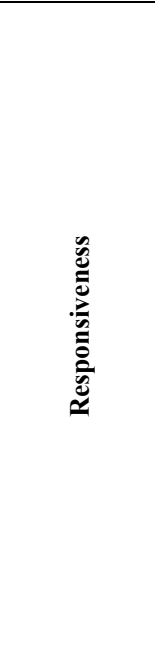 } & 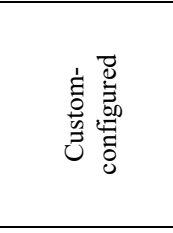 & $\begin{array}{l}\text { A supply chain focused on product configurability, where several product } \\
\text { features are customised among a set of limited options. Normally oriented } \\
\text { towards the end user. Workload before product's decoupling point is } \\
\text { smoothed by forecast. Extra capacities after decoupling point and design } \\
\text { for easy assembly or postponement are key elements for agility. Order } \\
\text { accuracy is a relevant factor in order to ensure fulfilment of customised } \\
\text { orders. }\end{array}$ \\
\hline & $\stackrel{0}{\stackrel{00}{<}}$ & $\begin{array}{l}\text { A supply chain focused on responsiveness to unpredictable demand. Used } \\
\text { for "exclusive" and short-lifecycle products. Asset utilisation is not } \\
\text { sufficiently relevant in the total cost. Workload has medium-sized peaks } \\
\text { and valleys. Customised/exclusive products and short order cycle are main } \\
\text { deliverables. Extra capacity and common components/materials are key } \\
\text { elements for agility. Normally oriented towards industrial customers. }\end{array}$ \\
\hline & $\frac{\frac{0}{a}}{\frac{0}{a}}$ & $\begin{array}{l}\text { A supply chain focused on solving problems, sometimes including } \\
\text { customer's emergency situations, or on proposing solutions, perhaps at the } \\
\text { level of engineering projects. Mainly used for products with high level or } \\
\text { added services. Typically price is irrelevant for customers due to } \\
\text { uniqueness of the solution. Capacity on standby, capacity pooling, and } \\
\text { reconfigurable processes are key factors for ensuring flexibility. } \\
\text { Relationships with customers tend to be shorter-term. }\end{array}$ \\
\hline
\end{tabular}

This last type is further split between a business event strategy in an entrepreneurial environment and a humanitarian response strategy in an emergency environment.

Management of the strategies requires different approaches to activities and challenges in the supply chains in general and network design in particular. Gattorna [22] provides a comparative analysis of the different strategies and his opinion on the differences in channels of distribution (or network design), is indicated in Table 6 .

The generic supply chain strategies and associated logistics networks all contribute to the objective of developing and implementing a supply chain that will be able to compete effectively on cost, service levels and whatever other performance indicators require. The solution is not 'one size fits all' but a process to develop a customised supply chain with support of modelling techniques such as centre-of-gravity analysis. 
Table 6: Supply chain strategies and network design [22].

\begin{tabular}{|l|l|}
\hline \multicolumn{1}{|c|}{ Supply chain strategy } & \multicolumn{1}{c|}{ Channels of distribution (Network design) } \\
\hline Continuous replenishment supply chain & Either direct or via trusted outlets \\
\hline Lean supply chain & $\begin{array}{l}\text { Wide distribution through multiple channels } \\
\text { for maximum accessibility }\end{array}$ \\
\hline Agile supply chain & $\begin{array}{l}\text { Fewer, more direct channels to access } \\
\text { consumers }\end{array}$ \\
\hline $\begin{array}{l}\text { Fully flexible supply chain - business } \\
\text { event }\end{array}$ & Limited and very targeted \\
\hline $\begin{array}{l}\text { Fully flexible supply chain - } \\
\text { humanitarian }\end{array}$ & As many as needed in a given situation \\
\hline
\end{tabular}

\section{CONCLUSION}

The purpose of this chapter was to explore the importance of heuristic modelling in the development of a suitable logistics network and most appropriate channel strategy. The need for and application of the centre-of-gravity analysis technique was presented and discussed with a practical example.

It is clear that there is not necessarily one best solution but an integrated system of nodes and links (facilities and channels) in the logistics network that provides for supply chains to compete effectively. The most appropriate channel strategy is highly likely product specific and developed for specific conditions in a specific supply chain.

\section{REFERENCES}

[1] Christopher, M., Logistics \& Supply Chain Management, Pearson Education Limited: Harlow, pp. 13-15, 2011.

[2] CSIR, The 10th Annual State of Logistics Survey for South Africa - 2013, Pretoria, pp. 7-13, 2014.

[3] CSCMP, 25th Annual State of Logistics Report, Lombard, p. 2, 2014.

[4] De Villiers, G., Nieman, G. \& Niemann, W., Strategic Logistics Management - A Supply Chain Management Approach, Van Schaik Publishers: Pretoria, pp. 213-214, 2008.

[5] Christopher, M., Logistics \& Supply Chain Management, Pearson Education Limited, Harlow, pp. 265-266, 2011.

[6] Stock, J.R. \& Lambert, D.M., Strategic Logistics Management, McGraw-Hill: New York, pp. 702-704, 2001.

[7] Rushton, A., Croucher, P. \& Baker, P., The Handbook of Logistics \& Distribution Management, Replika Press: India, pp. 50-58, 2010.

[8] Lambert, D.M. \& Stock, J.R., Strategic Logistics Management, Irwin: Boston, pp. 75-77, 1993.

[9] De Villiers, G., Fourth-party logistics, Logistics News, April 2007, p. 15, 2007.

[10] Gattorna, J.L., Strategic Supply Chain Alignment - Best Practice in Supply Chain Management, Gower Publishing Company: Aldershot, pp. 425-433, 1998.

[11] Stock, J.R. \& Lambert, D.M., Strategic Logistics Management, McGraw-Hill: New York, pp. 410-417, 2001.

[12] Ackerman, K., Warehousing Profitably, Ackerman Publications: Columbus, pp. 265267, 2011.

[13] Simchi-Levi, D., Kaminsky, P. \& Simchi-Levi, E., Managing the Supply Chain - The Definitive Guide for the Business Professional, McGraw-Hill, pp. 71-80, 2004. 
48 Transportation, Land Use and Integration: Perspectives for Developing Countries

[14] Blanchard, D., Supply Chain Management - Best Practices, John Wiley \& Sons: New Jersey, pp. 105-108, 2010.

[15] Simchi-Levi, D., Kaminsky, P. \& Simchi-Levi, E., Designing and Managing the Supply Chain-Concepts, Strategies, and Case Studies, McGraw-Hill, pp. 112-117, 2000.

[16] Coyle, J.J., Langley, C.J., Gibson, B.J., Novack, R.A. \& Bardi, E.J., Supply Chain Management - A Logistics Perspective, South-Western Cengage Learning: Mason, pp. 542-549, 2008.

[17] Bowersox, D.J. \& Closs. D.J., Logistical Management - The Integrated Supply Chain Process, McGraw-Hill: Singapore, pp. 554-561, 1996.

[18] Rushton, A., Croucher, P. \& Baker, P., The Handbook of Logistics \& Distribution Management, Replika Press: India, pp. 120-127, 2010.

[19] Stock, J.R. \& Lambert, D.M., Strategic Logistics Management, McGraw-Hill: New York, pp. 79-80, 2001.

[20] Perez, H.D., Supply chain strategies: Which one hits the mark?, CSCMP's Supply Chain Quarterly, Special Issue 2014, pp. 30-40, 2014.

[21] Gattorna, J.L., Dynamic Supply Chains - Delivering Value Through People, Prentice Hall: UK, pp. 51-56, 2010.

[22] Gattorna, J.L., Dynamic Supply Chains - Delivering Value Through People, Prentice Hall: UK, pp. 79-86, 2010. 